\title{
PENGEMBANGAN MEDIA PEMBELAJARAN TEMATIK TERPADU BERBASIS MACROMEDIA FLASH 8 DI KELAS IV SD
}

\author{
Yola Yolanda ${ }^{1}$, Mai Sri Lena ${ }^{2}$ \\ 1,2Pendidikan Guru Sekolah Dasar, Universitas Negeri Padang, Indonesia. \\ 1yolayolanda537@gmail.com, 2maisrilena@fip.unp.ac.id
}

\begin{abstract}
This research intends to develop an integrated thematic learning media based on Macromedia Flash 8 in grade IV SD Negeri 02 Tanjuang Puan Abai which is valid, practical and effective. And apply ADDIE type. Subjects were fourth grade teachers at SDN 02 Tanjuang Puan Abai and 21 fourth grade students at SD Negeri 02 Tanjuang Puan Abai. The research revealed: (1) integrated thematic learning media based on Macromedia Flash 8 in grade IV SD which was validated by experts was declared "very valid" with an overall validator score of $87.87 \%$, (2) teacher responses and student responses to learning media Thematically based on Macromedia Flash 8 in the fourth grade of SD obtained the "very practical" category with an assessment of $94.28 \%$ and $90.47 \%$, (3) The response of the effectiveness of Macromedia Flash 8 students to the learning in the fourth grade of elementary school with the category "High" with a percentage of $87.21 \%$.
\end{abstract}

Keywords: Integrated thematic, learning media, Macromedia Flash 8, ADDIE model, Motivation Questionnaire.

\section{ABSTRAK}

Penelitian bermaksud mengembangkan media pembelajaran tematik terpadu berbasis Macromedia Flash 8 di kelas IV SD Negeri 02 Tanjuang Puan Abai yang valid praktis dan efektif. Dan menerapkan tipe ADDIE. Subjek guru kelas IV SDN 02 Tanjuang Puan Abai dan 21 peserta didik kelas IV SD Negeri 02 Tanjuang Puan Abai. Penelitian mengukapkan: (1) media pembelajaran tematik terpadu berbasis Macromedia Flash 8 di kelas IV SD yang di validasi oleh para ahli dinyatakan "sangat valid" dengan nilai keseluruhan validator $87,87 \%$, (2) Tanggapan guru dan respon peserta didik terhadap media pembelajaran tematik berbasis Macromedia Flash 8 di kelas IV SD memperoleh kategori "sangat praktis" dengan penilaian $94,28 \%$ dan 90,47 \%, (3) Tanggapan efektivitas peserta didik Macromedia Flash 8 di kelas IV SD dengan kategori "Tinggi" dengan pesentase $87,21 \%$.

Kata kunci: Media pembelajaran, tematik terpadu, Macromedia Flash 8, model ADDIE, Angket Motivasi

\section{A. Pendahuluan}

Pendidikan merupakan hal penting untuk meningkatkan sumber daya manusia yang berkualitas. Salah satu kurikulum 2013, telah dikembangkan dan diterapkan di sekolah-sekolah. Kurikulum 2013 menekankan pembelajaran tematik 
menjadi sebuah tuntutan dan kebutuhan pokok dalam proses pembelajaran di sekolah dasar, sedangkan pembelajaran tematik merupakan suatu model pembelajaran terpadu.

Pembelajaran pada tematik berupa tema yang menggabungkan tiap pelajaran sehingga siswa memiliki pengalaman yang berarti (Effendi, 2009). Sedangkan Rusman (dalam Dania \& Elfia, 2020) yaitu proses pembelajaran menjadikan peserta didik menjadi subjeknya atau dikenal Sudent Center. Kemendikbud (2014) mengartikan bahwa pembelajaran tematik adalah sesuatu yang dapat mempermudah siswa dalam memfokuskan minat pada tema yang akan dipelajari. Kedepannya, siswa dapat mengembangkan pengetahuan tentang kemampuan dasar antara satu topik dengan topik lainnya, sehingga membuat siswa memiliki pemahaman yang lebih luas dan bermakna terhadap materi yang telah diperolehnya. Siswa harus menguasai pembelajaran mata pelajaran yang mengaitkan beberapa mata pelajaran membuat satu pelajaran tema. Agar siswa dapat memahami pembelajaran mata pelajaran secara komprehensif, tentunya diperlukan dukungan sarana pembelajaran berupa media.

Sesuai dengan materi yang terdapat pada kelas IV tema 7 subtema 1 pembelajran 1 terdapat pembelajaran Bahasa Indonesia yang berkaitan dengan mengenali pengetahuan baru tentang suku bangsa, IPA berkaitan dengan pengertian gaya dan pada pembelajran 2 terdapat pembelajaran SPDP yang berkaitan dengan mengenalitanda tempo dan tinggi rendah nada, Bahasa Indonesia mengosepkan pengetahuan baru tentang suku bangsa, IPA menjelaskan macam - macam gaya. Sesuai dengan materi guru dapat membuat media, Agar materi yang akan dipelajari tersebut dapat dipahami oleh peserta didik tentu perlu didukung oleh media pembelajaran.

Oneika dan maniladevi (2019) mengemukakan bahwa media pembelajaran yang digunakan untuk mempejelas pesan dan informasi yang akan disampaikan dalam pembelajaran.Masalah tidak terlepas dari seorang guru, sehingga guru perlu melakukan pembaharuan di berbagai bidang termasuk media 
pembelajaran (Azhar \& Arsyad, 2010).

Guru dapat melakukan berbagai cara dalam meningkatkan mutu pembelajaran, dengan memanfaatkan kemajuan ilmu pengetahuan dan teknologi. Menggunakan media pembelajaran dalam pemanfaatan teknologi akan memudahkan siswa dalam memahami pembelajaran (Dwiyono, 2017).

Berdasarkan observasi awal yang penulis jalankan di SDN 02 Tanjung Puan Abai pada tanggal 04 Desember 2020, guru sudah menggunakan sarana pembelajaran pada kurikulum 2013. Namun, sarana pembelajaran yang digunakan guru masih berbentuk konvesional, agar menjadikan peserta didik tidak cukup termotivasi, tidak cukup aktif dan menjadikan peserta didik susah mengetahui pembelajaran.

Hal ini diperkuat oleh wawancara yang penulis laksanakan bersama guru kelas IV SDN 02 Tanjung Puan Abai, guru masih memperlihatkan bahwa berupa gambar yang ditampilkan di depan kelas. Media pembelajaran yang berbasis teknologi belum pernah digunakan, guru mengaku mengalami ada masalah dalam memanfaatkan keberadaan teknologi. dimana pihak sekolah sendiri sudah menyediakan perangkat infocus. Hal ini disebabkan kurangnya pemahaman dan kemampuan guru membuat media pelajaran bertema teknologi.

Guru kelas IV pun menyadari pemanfaatan sarana pembelajaran menjadi keliru satu perihal yang terlalu penting didalam proses pembelajaran tematik terpadu. Penggunaan sarana dalam pembelajaran mampu menarik perhatian, menumbuhkan keingintahuan tinggi, memotivasi para pesertadidik jauh lebih aktif dan bersemangat dalam belajar.

Motivasi merupakan kapabilitas yang dimiliki oleh seseorang sehingga dapat menimbulkan semangat didalam melakukan kegiatan, bersumberkan asalnya dari luar dan dalam diri sendiri. Salah umpama motivsi didalam belajar yang bersumber berasal dari luar individu adalah pemanfaatan sarana pembelajaran yang menarik.

Penelitian terdahulu tentang Macromedia Flash telah dijalankan oleh (Setyawan et al., 2020) dan Setyaningsih dan Farida (2020). Setyawan dan Warkintin (2020) mengupas tentang Pengembangan Media Pembelajaran Berbasis 
Macromedia

Flash

Pada

Pembelajaran Tematik Kelas IV Tema

6 Sub Tema 1 Aku Dan Cita-Citaku, Setyaningsih dan Farida (2020) mengupas tentang Analisis Pemanfaatan Macromedia flash 8 Sebagai Upaya Pengembangan Media Pembelajaran Tematik Terpadu di Sekolah Dasar.

Dua penelitian terdahulu di atas mengembangkan media pembelajaran penggunakan Macromedia Flash untuk peserta didik sekolah dasar (SD). Karena telah banyak pengembangan menggunakan Macromedia Flash 8 yang berhasil dilaksanakan untuk peserta didik sekolah. Penulis tertarik untuk Mengembangankan media pembelajaran tematik terpadu berbasis Macromedia Flash di sekolah dasar. "Perangkat lunak yang memiliki animasi dimedia dalam pembelajaran bias digunakan dalam mendukung para guru memberikan materi dipelajari, dibuat menarik mungkin menggunakan komputer, laptop, notebook dan proyektor untuk aplikasi" (Wirasasmita \& Putra, 2018).

Kelebihan Macromedia Flash adalah dapat dengan mudah dipelajari dan dipahami tanpa memerlukan pengetahuan dasar yang tinggi dalam bidang ini. File yang dihasilkan sangat kecil, dan dapat menghasilkan file jenis jpg, mov, swf, gif, jpg, png, exe, html, cocok sesuaian dengan keperlukan. Penggunaan Macromedia Flash sebagai fasilitas pembelajaran, berfungsi bagi guru sebagai alat bantu dalam mempersiapkan sistem pembelajaran. Dengan terdapatnya fasilitas pembelajaran ini, akan memancing impuls dan memotivasi peserta didik sehingga pembelajaran lebih menggembirakan dan bermakna.

Berdasarkan latar belakang di atas maka rumusan masalah yang diperoleh yaitu: 1) Bagaimanakah pengembangan media pembelajaran tematik terpadu berbasis Macromedia Flash di kelas IV SD yang valid.? 2) Bagaimanakah pengembangan media pembelajaran tematik terpadu berbasis Macromedia Flash di kelas IV SD yang praktis.?

Tujuan penelitian yaitu: 1) Mengembangkan media pembelajaran tematik terpadu berbasis Macromedia Flash 8 di kelas IV SD yang valid. (2) Mengembangkan media pembelajaran tematik terpadu berbasis Macromedia Flash 8 di kelas IV SD yang praktis. 


\section{B. Metode Penelitian}

\section{Jenis Penelitian}

Penelitian

berupa

pengembangan R\&D. Karena hasil penelitian dapat menciptakan produk baru. Penelitian pengembangan merupakan suatu cara dan tahaptahap dalam mengembangkan sebuah product untuk menyempurnakan sebuah product yang telah ada, Metode pengembangan yaitu penelitian yang dipakai dapat membuat suatu produk dan menguji keefektifannya (Sugiono, 2017). ssProduk akhir dari pengembangan dan penelitian ini berupa CD.

Berdasarkan

beberapa pendapat ahli disimpulkan bahwa penelitian pengembangan, kesimpulannya penelitian dan pengembangan dapat menghasilkan produk yang harus diuji terlebih dahulu, tapi model yang penulis gunakan adalah model ADDIE.

\section{Waktu dan Tempat Penelitian}

Penelitian dilakukan pada SDN 02 Tanjuang Puan Abai, Kecamatan Sangir Batang Hari, Kabupaten Solok Selatan. Analisis dilakukan tanggal 12 sampai 16 Maret 2021.

\section{Target/Subjek Penelitian}

Subjek analisis yaitu 1 seorang guru kelas IV di SD Negeri 15 Negeri 02 Tanjuang Puan Abai dan peserta didik sebanyak 21 orang kelas IV di SD Negeri Negeri 02 Tanjuang Puan Abai. Untuk melihat kevalidan media pembelajaran tematik dilakukan validasi menggunakan penilaian ahli (expert judgment).

\section{Prosedur}

Rancangan digunakan dalam penelitian yaitu ADDIE menurut Branch (dalam Ratumanan 2019: 70 73) ada 5 bagian dalam pengembanganya yaitu, dilakukanya analisis, desain, pengembangan, implementasi, evaluasi.

\section{Data, Instrumen dan Teknik Pengumpulan Data}

Jenis data berupa kualitatif dan kuantitatif yaitu hasil uji kepraktisan, uji validitas dan efektifan. Data pertama bersifat hasil validasi tempat pembelajaran tematik terpadu berbasis macromedia flash 8 kelas IV SD yang diperiksa oleh validator, seperti dosen ahli materi, ahli tempat dan juga ahli kegrafikaan. Data kedua pelaksanaan percobaan. Pada percobaan ini hasil uji praktikalitas yaitu respon guru dan respon peserta didik Data ketiga didapatkan dari 
percobaan angket motivasi pada macromedia flash 8 dikelas IV SD. Jadi data diperoleh yaitu validity, practicality and effectiveness produk yang dikembangkan.

Instrumen pengumpulan data didalam penelitian ini berupa angket yang validasi, lembar angket tanggapan guru serta lembar angket tanggan peserta didik dan keefektifan produk yang ujicobakan.

Teknik pengumpulan data berguna dalam mendapatkan sebuah data yang telah dianalisis. data diambil menggunakan lembar validasi dan lembar angket praktikalitas Dan lembar efektifitas. Lembar validasi digunakan meliputi lembar validasi untuk pakar materi, pakar media dan pakar kegrafikaan. Angket digunakan merupakan angket untuk respon guru dan respon peserta didik. Jenis lembar angket digunakan berupa angket tertutup yang berarti respon bisa memilih jawaban yang sudah tersedia, skala yang digunakan yaitu berskala Likert bersama berskala 5 .

\section{Teknik Analisis Data}

Data yang diambil dalam
penelitian yaitu validasi media
pembelajaran tematik oleh ahli
masing. Hasil yang diambil dalam

pelaksanaan percobaan berwujud data kepraktisan media pembelajaran tematik berbasis macromedia flash 8 di kelas IV SD Dan data keefektifan yang diambil dari lembar angket motivasi pada macromedia flash 8 setelah media ditampilkan. Data yang sudah diperoleh sesudah itu dianalisis adalah:

\section{Analisis Data Validasi Media Pembelajaran Tematik Terpadu}

Hasil media pada pembelajaran pada tematik terpadu diperoleh, di lakukan analisis pada semua prospek yang dihidangkan pada tabel dengan memakai skala Like. Kriteria penskoran media pembelajaran tematik terpadu memakai penilaian (Ridwan \& Sunarto, 2015).

Tabel 1. Daftar Penskoran Validitas Media Pembelajaran Tematik.

\begin{tabular}{cc}
\hline Skor & Kategori \\
\hline 1 & Sangat kurang baik \\
\hline 2 & Kurang baik \\
\hline 3 & Cukup baik \\
\hline 4 & Baik \\
\hline 5 & Sangat baik
\end{tabular}

(Modifikasi Ridwan \& Sunarto, 2015) 
Selanjutnya untuk menilai validitas memakai rumus (Purwanto, 2013):

$$
\mathrm{NP}=\frac{R}{S M} \boldsymbol{x} 100 \%
$$

\section{Keteranganya:}

NP Nilai persen yang dicari

$\mathrm{R}$ perolehan skor

SM Skor Maksimum

Selain itu, untuk mengukur perhitungan dan nilai akhir hasil validitas digunakan rumus Ridwan \& Sunarto, (2015) adalah sebagai berikut.

$$
\mathbf{X}=\frac{£ \mathbf{X i}}{n}
$$

\section{Keterangannya:}

$X$ Rerata

$£ X i$ Jumlah nilai dari tiap validator

n Jumlah validator

Tabel 2. Kategori Kevalidan Media

\begin{tabular}{|c|c|c|}
\hline Reantang & Keterangan & Data akhir yang dihitung dari \\
\hline $81 \%$ & Sangat Valid & kuesioner \\
\hline $100 \%$ & & menggunakan \\
\hline $61 \%-80 \%$ & Valid & (2013)adalah sebagai berikut: \\
\hline $41 \%-60 \%$ & Cukup Valid & $\mathrm{NP}=\frac{R}{S M} x 100 \%$ \\
\hline $21 \%-40 \%$ & Kurang Valid & Tabel 4. Kategori Kepraktisan Media \\
\hline $0 \%-20 \%$ & Tidak Valid & Pembelajaran tematik terpadu. \\
\hline \multirow{3}{*}{\multicolumn{2}{|c|}{ (Modifikasi Purwanto, 2013) }} & Kategori \\
\hline & & Sangat Praktis \\
\hline & & $76 \%-85 \%$ \\
\hline
\end{tabular}
Pembelajaran Tematik

\section{Analisis Data Praktikalitas} Media Pembelajaran Tematik Terpadu

Teknik analisis praktikalitas kegunaannya yaitu untuk analisis data pengamatan keterlaksanaan angket guru dan lembar tanggapan peserta didik menggunakan rumus (Purwanto, 2013)

$\mathrm{NP}=\frac{R}{S M} x 100 \%$

Tabel 3. Skala Penilaian Angket

Guru dan Angket Peserta Didik

\begin{tabular}{cl} 
Rentang & Kategori \\
\hline 5 & Sangat Setuju \\
\hline 4 & Setuju \\
\hline 3 & Cukup Setuju \\
\hline 2 & Kurang Setuju \\
\hline 1 & Tidak Setuju
\end{tabular}

\section{Modifikasi dari Siregar}

(2013:50) 


\begin{tabular}{ll}
\hline $60 \%-75 \%$ & Cukup Praktis \\
\hline $55 \%-59 \%$ & Kurang Praktis \\
\hline $0 \%-54 \%$ & Tidak Praktis
\end{tabular}

sebagai berikut:

Modifikasi dari Purwanto (2013:103)

3. Analisis Data efektivitas Media Pembelajaran Tematik Terpadu

Analisis Data efektivitas Media Pembelajaran Tematik Terpadu. Teknik analisis untuk telaksananya angket respon dapat dari peserta didik pada motivasi belajar terhadap sarana yang ditampilkan.

Tabel 5. Skala Penilaian Angket Peserta Didik

\begin{tabular}{ccc}
\hline \multicolumn{2}{c}{ RENTANG } & Kategori \\
\cline { 1 - 2 } Positif & Negatif & \\
\hline $\mathbf{5}$ & $\mathbf{1}$ & $\begin{array}{c}\text { Sangat } \\
\text { Setuju }\end{array}$ \\
\hline $\mathbf{4}$ & $\mathbf{2}$ & Setuju \\
\hline $\mathbf{3}$ & $\mathbf{3}$ & $\begin{array}{c}\text { Cukup } \\
\text { Setuju }\end{array}$ \\
\hline $\mathbf{2}$ & $\mathbf{4}$ & $\begin{array}{c}\text { Kurang } \\
\text { Setuju }\end{array}$ \\
\hline $\mathbf{1}$ & $\mathbf{4}$ & $\begin{array}{c}\text { Tidak } \\
\text { Setuju }\end{array}$ \\
& & Setuja
\end{tabular}

Modifikasi Depdinas (2013:50)

Data angket dinilai menggunakan rumus perhitungan data angket dianalisis menggunakan rumus dari depdiknas (2003) yaitu
Nilai Motivasi =

$\frac{\text { skor yang diperoleh }}{\text { Skor Maksimum }} \times 100 \%$

Tabel 6. Kategori respon peserta didik pada angket motivasi

\begin{tabular}{|l|l|}
\hline Rentang & Kategori \\
\hline $\begin{array}{l}\leq 86 \%-\text { ke } \\
\text { atas }\end{array}$ & Tinggi \\
\hline $\mathbf{6 0 \% - 7 9 \%}$ & Sedang \\
\hline$\geq 59 \%$ & Rendah \\
\hline
\end{tabular}

(Depdiknas 2003)

\section{Tahap Analysis (analisis)}

Tahap analisis diawali dengan observasi dan wawancara terhadap pihak sekolah. Dari hasil observasi dan wawancara diketahui bahwa permasalahan dalam pembelajaran guru belum memanfaatkan teknologi untuk mengembangkan media pembelajaran tematik yang komprehensif. Meskipun pemanfaatan teknologi di SD 02 Tanjuang Puan Abai terbatas atau jarang digunakan untuk pembelajaran. Setelah itu, ide tema KD dilakukan.

\section{Tahap Design (Perancangan)}

Dalam perancangan tersebut peneliti merancang sebuah media pada pembelajaran tematik berbasis Macromedia flash 8 Media pembelajaran yang dirancang untuk 
memfasilitasi

guru

untuk

menyampaikan

informasi

pembelajaran serta memudahkan

dalam menguasai materi yang

diajarkan oleh guru yaitu:

\section{Halaman Loading}

Halaman yang terdapat pada loading yaitu halaman pertama yang akan muncul ketika media pembelajaran tematik terpadu dijalankan.

2. Halaman Selamat Datang

Halaman kedua ini adalah halaman yang mana akan muncul tema serta subtema yang akan dipelajari dan peserta didik dapat menekan tombol "mulai" untuk memulai pembelajaran.

3. Halaman Menu

Halaman menu berisi menu-menu pembelajaran yang akan dilihat dan dipelajari peserta didik.

\section{Halaman menu 1 profil}

Halaman ini berisi tentang biodata diri penulis.

5. Halaman menu 2 KD pembelajaran Halaman ini berisi materi 1dan 2 yang dilengkapi dengan gambar pendukung.

6. Halaman menu 3 tujuan
pembelajaran

7. Halaman ini berisi materi pembelajaran 1 dan 2 yang dilengkapi dengan gambar pendukung.

8. Halaman menu 4 pembelajaran materi

Halaman ini berisi materi pembelajaran 1 dan 2 dilengkapi dengan gambar pendukung.

9. Halaman menu 5 evaluasi pembelajaran

Menu evaluasi berisi soal pilihan ganda serta jawaban yang akan muncul setelah siswa telah menjawab pertanyaan.

10. Halaman menu 6 keterangan simbol

Halaman ini menampilkan semua simbol yang terdapat pada media pembelajaran.

\section{Tahap Development (Pengembangan)}

Tahap mengembangan media pada pembelajaran tematik berbasis Macromedia flash 8 meliputi validasi terhadap media pembelajaran tematik terpadu, yang bertujuan untuk meminta pendapat para ahli, kemudia media pembelajaran direvisi hingga memperoleh media pembelajaran tematik terpadu yang valid. Media pembelajaran yang sudah valid di ujicobakan Untuk peserta didik sekolah dasar kelas empat memahami kegunaan media pembelajaran tematik terpadu. 
Tahapan pengembangan yaitu;

\section{Validasi Media Pembelajaran}

Tahap ini yang dirancang dan dikembangkan oleh peneliti diteruskan sesuai kegiatan yang akan validasi oleh ahli sesuai keahliannya yang terdiri dari 3 orang; validator materi, media dan grafik. Menurut hasil validasi yang berisi saran validator, setelah media pembelajaran tematik hasilnya direvisi. Data revisi dipakai dalam memperbaiki media yang telah dibuat dengan menuangkan saransaran validator. Sehingga menghasilkan media pembelajaran tematik yang valid.

Tabel 7. Hasil validasi media pembelajaran tematik

\begin{tabular}{|c|l|c|c|}
\hline No. & Validator & $\begin{array}{c}\text { Skor } \\
\text { Total }\end{array}$ & Ket \\
\hline 1 & Materi & $93 \%$ & SV \\
\hline 2 & Media & $84,61 \%$ & V \\
\hline 3 & Kegrafikan & $86 \%$ & V \\
\hline & Rata -Rata & $\mathbf{8 7 , 8 7 \%}$ & \\
\hline & Keterangan & $\begin{array}{c}\text { Sangat } \\
\text { Valid }\end{array}$ & \\
& & &
\end{tabular}

Keterang;

SV = Sangat Valid

$\mathrm{V}=$ Valid

$X=\frac{€ X \mathbf{i}}{n}$

$$
\begin{gathered}
X=\frac{93+84,61+86}{3} \times 100 \% \\
=87,87 \%
\end{gathered}
$$

Tahap Implementation (Penerapan)

Tahap impementasi dilakukan setelah media pembelajaran tematik terpadu berbasis Macromedia flash 8 di kelas IV SD yang dikembangkan telah dinyatakan valid oleh para ahli. media pada pembelajaran tematik berbasis Macromedia flash 8 dikelas IV SD yang dinyatakan sudah valid kemudian diujicobakan di kelas IV SDN 02 Tanjuang Puan Abai.

\section{Tahap Evaluation (Evaluasi)}

Tahap evaluasi dilakukan setelah uji coba di kelas IV SD Negeri Tanjuang Puan Abai. Fase valuasi peneliti untuk mengevaluasi kualitas proses pembelajaran. Standar evaluasi bertujuan untuk mengidentifikasi pemahaman terhadap media pada pembelajaran tematik berbasis Macromedia flash 8 dikelas IV SD melalui uji praktikalitas dan efektifitas. Uji praktikalitas dan efektifitas dilakukan untuk memperoleh informasi apakah media pembelajaran tematik terpadu berbasis macromedia flash 8 untuk 
memotivasi peserta didik dikelas IV SD dalam pembelajaran.

Hasil penilaian praktikalitas respon guru sebagai berikut:

Data praktikalitas diperoleh dari guru kelas IV SD Negeri 02 Tanjuang Puan Abai dengan cara memberikan lembar penilain berupa angket yaitu;

Tabel 8. Hasil praktikalitas media pembelajaran tematik

\begin{tabular}{ccccccc}
\hline \multirow{2}{*}{ Nama } & \multicolumn{5}{c}{ Aspek nilai pada materi } \\
\cline { 2 - 6 } & 1 & 2 & 3 & 4 & 5 & 7 \\
\hline Sarli S.Pd & 4 & 4 & 4 & 5 & 4 & 4 \\
\hline Jml Skor & & & 32 & \\
\hline Presentas & & & $91,42 \%$ & \\
e & & & & &
\end{tabular}

\section{Keterang : Sangat Praktis}

Skor yang diperoleh $(R)=32$

Skor Maksimum (SM) = jumlah

indikator $\mathrm{x}$ skor maksimal

$=7 \times 5$

Skor Maksimum (SM) $=35$

$\mathrm{NP}=\frac{R}{S M} \times 100 \%$

$\mathrm{NP}=\frac{32}{35} \times 100 \%$

$\mathrm{NP}=91,42 \%$

Dari hasil akhir persentase angket respon guru di atas yaitu 91,42 \% dapat dikatakan "sangat praktis" pada kategori penilaian menurut
(Purwanto, 2013) yaitu termasuk kategori pertama dengan presentase 86-100\%, untuk itu hasil praktikalitas media pembelajaran tematik berbasis Macromedia Flash 8 pada kelas IV SD ini sudah praktis untuk di gunakan.

Tabel 9. Hasil penilaian

praktikalitas respon peserta didik kelas IV

\begin{tabular}{|c|c|c|c|c|}
\hline $\begin{array}{l}\text { Jml pese } \\
\text { rta didi k }\end{array}$ & $\begin{array}{l}\text { jml } \\
\text { skor }\end{array}$ & $\begin{array}{r}\text { Jmlh } \\
\text { pesen } \\
\text { tase } \\
\%\end{array}$ & $\begin{array}{l}\text { Jmlh } \\
\text { Rata- } \\
\text { Rata } \\
\%\end{array}$ & Kriteri a \\
\hline 21 & 570 & $\begin{array}{c}542,8 \\
2 \%\end{array}$ & $\begin{array}{c}90,47 \\
\%\end{array}$ & SP \\
\hline
\end{tabular}

respon peserta didik yaitu 90,47\% dapat dikatakan "sangat praktis" dalam kategori penilaian menurut (Purwanto, 2013) termasuk dalam kategori pertama dengan persentase sebesar $86-100 \%$, untuk itu hasil praktikalitas media pada pembelajaran tematik berbasis Macromedia flash 8 dikelas IV SD ini sudah sangat praktis untuk di gunakan.

\section{Efektivitas Media Pembelajaran}

Data hasil efektifitas didapatkan setelah media diujicobakan kepada peserta didik berupa angket motivasi. 
Tabel 10. Hasil penilaian efektivitas respon peserta didik kelas IV

\begin{tabular}{|l|l|l|l|l|}
\hline Jm & j & J & J & Kri \\
I & m & ml & ml & te \\
pe & I & pe & Ra & ria \\
ta & s & se & ta & \\
did & o & as & - & \\
ik & r & e & $\%$ & \\
& & $\%$ & & \\
\hline $\mathbf{2 1}$ & 542 & 971, & 80,9 & TI \\
&, 82 & 3 & 4 & $\mathbf{N}$ \\
& $\%$ & $8 \%$ & $\%$ & $\mathbf{G}$ \\
& & & & Gl \\
\hline
\end{tabular}

Dari nilai akhir Angket motivasi respon peserta didik yaitu $87,21 \%$ dapat dikatakan "Tinggi" pada kategori penilaian menurut (Depdiknas 2003) yaitu termasuk kategori pertama dengan presentase 86 - $100 \%$, untuk itu hasil "Tinggi" jadi penggunan media sudah dapat digunakan untuk memotivasi dalam belajar.

Hasil penelitian ini menunjukkan bahwa penggunaan media pembelajaran tematik terpadu berbasis Macromedia Flash 8 berpengaruh positif terhadap pembelajaran tematik pada materi Tema tujuh, Subtema satu, pembelajaran satu dan pembelajaran dua dikelas IV Sekolah dasar Dalam proses pembelajaran menggunakan media pembelajaran tematik terpadu berbasis Macromedia Flash 8 dapat memberikan banyak manfaat, yaitu efisien dalam penyampaian materi dan mudah dipahami sehingga meningkatkan minat belajar peserta didik terhadap materi Tema tujuh, Subtema satu, pembelajran satu dan pemebelajaran dua. Sesuai pada penelitian yang pernah dilakukan oleh Setyawan dan Warkintin 2020, membahas Pengembangan Media Pembelajaran Berbasis Macromedia Flash Pada Pembelajaran Tematik Kelas IV Tema 6 Sub Tema satu Aku Dan Cita-Citaku, yang pada hasil penelitiannya, peserta didik dapat lebih memahami materi sebesar $82 \%$ kesimpulanya setuju bahwa pembelajaran mudah dimengerti dengan penggunaan media.

\section{Kesimpulan}

Penelitian yang di lakukan peneliti menghasilkan media pembelajaran tematik berbasis Macromedia flash dikelas IV Sekolah Dasar mengaplikasikan cara ADDIE. Tim ahli yang terdiri dari materi, media dan kegrafikaan menyatakan media 
pada pembelajaran tematik berbasis Macromedia flash 8 dikelas IV SD valid dan layak digunakan. Hal ini dapat diketahui melalui hasil penilaian akhir $87,87 \%$ dengan kategori sangat valid. Guru kelas IV SD Negeri 02 Tanjuang Puan Abai juga menyatakan media pembelajaran tematik terpadu berbasis Macromedia flash 8 medapatkan kategori "sangat praktis" persentase sebesar "91,42\%" dan hasil tanggapan peserta didik terhadap media pada pembelajaran tematik berbasis Macromedia flash 8 dikelas IV SD memperoleh kategori sangat praktis persentase $90,47 \%$. Dan efektivas respon peserta didik dari media melalui angket dengan persentase sebesar 80,94\%. Jadi media pada pembelajaran tematik berbasis Macromedia flash 8 dikelas IV SD yang dikembangkan dengan model ADDIE dinyatakan valid dan praktis digunakan di sekolah dasar untuk pembelajaran tematik terpadu materi Tema tujuh, Subtema satu, pembelajran satu dan pembelajaran dua.

\section{DAFTAR PUSTAKA}

Azhar, \& Arsyad. (2010). Media Pembelajaran. Rajawali Pers.

Dania, R., \& Sukma, E. (2020).
Peningkatan

Proses

Pembelajaran Tematik Terpadu Menggunakan

Model

Cooperative Learning Tipe

Think Pair Share di Sekolah

Dasar. Jurnal Pendidikan

Tambusai, 4(3), 2624-2636.

Dwiyono. (2017). pengembang media pembelajaran berbasis game edukasi sebagai media pe,mbelaajaran interaktif pada kompetensi dasar mendeskripsikan penggunaan peralatan tangan (Hand Tools) dan pelaratan bertenaga (Power Tools). E-Jurnal Universitas Negeri Yogyakarta, Vol 7 No 4. Effendi, M. (2009). Kurikulum dan Pembelajaran: Pengantar Ke Arah pemahaman KBK, KTSP dan SBI. FIP Universitas Negeri Malang.

Kemendikbud. (2014). Konsep dan Implementasi Kurikulum 2013. Kementrian Pendidikan dan Kebudayaan.

Oneika, SE \& Maniladevi, M. 2019. Pengaruh Media Pembelajaran CS3 Berbasis Android Terhadap Kamampuan Berpikir Geometris Siswa SDN 01 Benteng Pasa Bukit Tinggi. E- Journal 
Pembelajran Inovasi, Jurnal

Pendidikan IImiah Dasar, 7 (11)

Purwanto, N. (2013). Prinsip-Prinsip

dan Teknik Evalusi Pengajaran.

Remaja Rosdakarya.

Ridwan, \& Sunarto. (2015). Pengantar

Statistika. Alfabeta.

Setyawan, Warkintin, \& Januariko, Y.

(2020). Pengembangan media pembelajaran berbasis macromedia flash pada

pembelajaran tematik kelas iv tema 6 sub tema 1 aku dan cita- citaku. Sugiono. (2017). Metode Penelitian

Kuantitatif, Kualitatif dan R\&D. Alfabeta.

Wirasasmita, R. H., \& Putra, Y. K. (2018). Pengembangan Media Pembelajaran Video Tutorial Interaktif menggunakan Aplikasi Camtasia Studio dan Macromedia Flash. EDUMATIC: Jurnal Pendidikan Informatika, $1(2)$, 35.

https://doi.org/10.29408/edumat ic. $11 \mathrm{i} 2.944$ 